\title{
On Basic Principles in Contrastive Analysis
}

\author{
Li-juan Wei ${ }^{\mathrm{a},{ }^{* 1}}$, Cong-ying Liu ${ }^{\mathrm{a},{ }^{* 2}}$ \\ ${ }^{a}$ Handan College, Handan, Hebei Province, China
}

\begin{abstract}
This paper describes some basic concepts in contrastive linguistics, and discusses its function in language teaching. And it compares the English proverbs containing the animal word horse with the equivalent Chinese proverbs. It aims to find the correspondence of the animal word horse in English and Chinese languages and illustrate the cultural phenomenon behind the translation. This paper finds out that the correspondence is very important and can help to understand the languages and the cultures and contribute to the teaching of language. Relevant study should be based on the cooperation and effort of both linguistics and teachers.
\end{abstract}

Index Terms: Concepts; Function; Correspondence; Translation; Application

(C) 2011 Published by MECS Publisher. Selection and/or peer review under responsibility of the International Conference on E-Business System and Education Technology

\section{Introduction}

Contrastive analysis is becoming more mature with more theories and methods developed. It's important to master and study it. This paper will introduce some basic concepts in contrastive linguistics first, and then it will choose one problem as the concern of contrastive analysis.

\section{What Is Contrastive Linguistics?}

The importance and position of contrastive linguistics should be made clear. According to the forefather of linguistics, Saussure, linguistics can be studied from two aspects, namely diachronic study and synchronic study. Diachronic study is about the etymology, concerning historical and comparative study of one language. While synchronic study is about the language study at a certain period of time, and it's always about descriptive linguistics, concerning language universals, language typology and contrastive linguistics. Therefore, contrastive linguistics can be classified as synchronic study of inter-lingual relations.

Second, the definition of contrastive linguistics is not simple. There're a lot of different definitions. According to Saussure, it's a branch of linguistics which aims at a systematic synchronic description of two or more languages in order to determine the similarities and differences between them and to find out the implications of such similarities and differences for language related activities. On terminology, it's regarded as a more formal and general term and it's also called contrastive analysis, or more pedagogically oriented as 
applied contrastive linguistics studies. It can be a method in foreign language teaching, a contrast study in a specific area, or a hypothesis about a certain linguistic phenomenon.

Third, the classification of contrastive linguistics can be based on a theoretical basis and a applied basis. Theoretical contrastive analysis aims at explore the contrastive analysis patterns and theoretical frame, and to analyze and describe the similarities and differences between two or more languages. In this way, the concept of equivalence and correspondence will be settled. Language is system. The study of it can be divided into the study of phonetics, lexicon, syntax, and semantics. Thus contrastive analysis can be first divided into the study of phonetics, lexicon, syntax, and semantics in accordance. While applied contrastive analysis is to apply the theory of contrastive analysis to teaching, translation or dictionary-design. The main purpose is for foreign language teaching. It aims at studying specific language phenomenon, such as the different usages of English and Chinese articles. Teachers must solve three questions. First one is why contrastive analysis is instructive in foreign language teaching. Second one is how to apply contrastive analysis to FLT. Third one is what's the relationship between contrastive analysis and applied linguistics. For the first one, teachers must analyze the factors in FLT, study the psychology of learners, and know more about the learning process. For the second one, teachers must study and analyze the important stages of learning such as course design, textbook, classroom teaching and FL testing. They should do the detailed comparison of language differences. For the third one, they must know what function contrastive analysis has in the long course of linguistics. They shall evaluate its importance and significance.

Fourth, the importance of contrastive linguistics should be realized. U.S. linguists said that there's a need for an efficient way of learning a foreign language. C.C. Fries thought that with a good comparison between native and foreign languages, the teacher can better predict the difficulties [1]. Benjamin Lee Whorf was the first person to use the term, contrastive analysis [2].

Fifth, the possibility of performing contrastive analysis is great. There's comparability between languages.

\section{Macro Linguistic Considerations and Micro Linguistic Considerations}

Concerning the macro linguistic considerations, there're extra linguistic factors, such as time or temporal factor, space or spatial factor, and society or social factor. First, there's variation according to the temporal factor. Different historical periods have different ways of speaking or language. In English, there're Old English, Middle English, and modern English. The different languages in different periods can be compared. Second, there's variation according to spatial factor or the language users in different areas. Different people in different regions may have their dialects and sub-dialects. They may be national or regional. There are sociolects too, which are based on the social status of the speaker, such as cockney, which is a kind of English spoken by poor people living in East London. One distinct feature is the dropping of the [h] sound, as in "Henry Higgins" spoken by the flower girl in the film My Fair Lady. Third, there's variation according to the language use. It's based on the context of communication, including subject matter, content, purpose of talking, means of talking, audience type, occasion, etc. Halliday gave a classification of language into field, mode and tenor. Field means specific area of language use, whether it is belonging to a certain occasion or a certain vocation, such as legal English and scientific English. Let's compare two sentences.

You can rectify this fault if you insert a wedge.

Rectification of this fault is achieved by inserting a wedge.

Sentence $\mathrm{a}$ is a normal one, while sentence $\mathrm{b}$ is a scientific one as far as field is concerned. It has the noun which is derived for the verb, and the passive voice is used, which is the symbol of being scientific and formal [3].

The mode is the channel, the genre, or the rhetorical mode, such as narrative, didactic, persuasive, phatic communication types.

The tenor reveals the relation between speakers. It's usually divided into five types, frozen, formal, consultative, casual, and intimate languages. The meaning of asking others to go upstairs can be seen in different tenors. "Visitors should make their way at once to the upper floor by way of staircase." belongs to 
frozen language. "Visitors should go up the staircase at once" belongs to formal language. "Would you mind going upstairs right away" belongs to consultative language. "Time you all went upstairs now" belongs to casual language. "Up you go, chaps" belongs to intimate language. [4]

Concerning the micro linguistic considerations, different levels of language organizations are observed, such as phonological, lexical, grammatical, semantic, textual, and pragmatic levels. Language is full of levels, which is called a system of systems [5].

The general procedures in carrying out a more practically oriented contrastive analysis includes four steps, the identification of the problem area, description by using the framework, juxtaposition by putting the separate descriptions of the two languages side by side, and deciding what is to be compared with what based on intuitive judgments of competent bilingual speakers, comparison which comes last.

The general procedures in carrying out a more theoretically oriented contrastive analysis include six steps.

First, the author must determine the scope of his study as specific as possible. In other words, that is to say, he must narrow it down.

Second, he should review the previous literature by stating the separate study already alone in the area and separate studies of the two languages in the area. This is similar to what is called the literature review.

Third, he should choose a theoretic model or framework, which depends on the purpose and level of the study. Otherwise, it will not be feasible enough to make it as valid as required.

Fourth, he must collect sufficient data for analysis. That is to say, sufficient data must be based on the large number of subjects and samples.

Fifth, he should do the contrastive analysis of the data both qualitatively and quantitatively. Only in this way, can the true value be shown and tested.

Sixth, he must sum up the results. Finally, complete content and organizational editing before formatting. Please take note of the following items when proofreading spelling and grammar:

\section{The Application of Contrastive Analysis in Foreign Language Teaching}

Contrastive analysis is most useful in foreign language teaching. In China, people call English their foreign language. American linguist Krashen distinguished between language learning and language acquisition. The former refers to the learning in class, while the latter refers to learning in natural environment. In china, most school children even college students still learn English mainly in class, taught by teachers. According to behaviorists and structuralists, foreign language learning is related to language transfer from native language to foreign language. When there're more similarities between the two languages, there's favorable transfer. When there're more differences, there's unfavorable transfer. The goal of foreign language teaching is to make good use of favorable transfer and overcome unfavorable transfer. While in modern studies, linguists find that this is only partly true. Some similarities will lead to unfavorable transfer, and some differences may lead to favorable transfer. According to Dulay and Burt, transfer is meaningless. Cook found that the learning of foreign language is similar to that of native language. In general, the two different studies should be integrated. In foreign language teaching, the two studies should be utilized based on different occasions, different students, and different teachers. The studies give out tow important methods in teaching, that is contrastive analysis and error analysis. As to contrastive analysis, foreign language teachers should fully understand the reasons for students to make mistakes and he can prevent and correct the mistakes. Teachers should study students' psychology, and compare the two languages. While error analysis advocates the universal rules of languages. Corder distinguished errors from mistakes. Errors are regular reflecting students' linguistic ability, and students should think about their learning strategies. Mistakes are due to physical or psychological states, such as fatigue, nervousness or fear. Teachers should first collect enough data such as the age of students, their native language, and stage of learning. Find the mistakes and errors. Study the reasons, whether it be of strategies or accidents. Contrastive analysis can help language learners with their correct prediction. Lado said that people could predict and describe the difficult linguistic structures and rules and the easy ones. 
When there's similarity, there will be favorable transfer, while when there's difference; there will be more likely with unfavorable transfer. This is only partly true. There're a lot of factors besides native language, one being the learning environment. In natural environment, transfer cannot be the main factor, but in classroom environment it is very influential. In natural environment, language learners are open to rich vocabulary and usage, and have more chances to overcome it. But in classroom, students only learn from the book and teacher without much chance to get involve in the natural environment, thus be limited to a small scope of vocabulary and usage, and have less chance to correct the mistakes. Another factor is the age of learners. Child learners tend to be less concerned with transfer than adult learners. Child learners tend to be suffering from the structure and complexity of the language in general. While adult learners tend to analyze the foreign language by means of mother tongue.

Contrastive analysis can be used in foreign language teaching. First, in the design of textbooks, textbooks always follow the order of complexity. The easiest comes first, and the most difficult comes latest. But teachers should consider some applications of ca. some experts still have different ideas towards ca. but in the design of phonetics, contrastive analysis is widely used. Textbooks describe the differences of the English and Chinese sounds, and point out the possible mistakes due to transfer. Maybe this is due to the fact that there're only a relatively small number of sounds but the vocabulary and grammar are far more complex.

Second, contrastive analysis is efficient in testing. A. Davies ed. considered contrastive analysis as valid. Contrastive analysis can generalize some mistakes and some difficulties [6]. It's true that in the design of test, contrastive analysis is commonly used, since most of the test is made by Chinese teachers. In the multiple choice of 1999 CET, there's one exercise "Fireworks, which were invented several ago in China, were brought to Europe by Marco Polo." The items are "century, centuries, months, month". The ones of "century" and "month" are interferences of mother language. In Chinese, there's no suffix. The design is based on the idea of transfer.

Thirdly, in class, teachers should take good advantage of contrastive analysis to predict the possible mistakes and help with the correct realization of differences and similarities. Contrastive analysis will be a kind of habit which will do good, and it will be a method instead of universal rule. This method can help students with better understanding and memorizing the words and structure. For example, the usage of "want" is not very easy regarding the right register. Students make sentences like "I want to borrow your dictionary." This is ok in china to say "wo xiang yao jie ni de shu". But in English "want" is not equivalent to "xiang" in all cases. In this sentence, "want" should be replaced with "would like to". The latter is more polite and used to express request, invitation, and asking. This kind of contrastive analysis-based explanation will help students overcome the transfer and understand better the language. In class, one of the difficulties is the understanding of animal words and proverbs. There're similarities and differences between animal words and their metaphorical usage in Chinese and English. The contrastive analysis' study is based on two things, one being the fact that human beings are basically one kind of animals, which are alike in appearance, physical state, psychological state, behaviors and characteristics, and the other being the fact that a lot of animated characters are rich in cultural, historical, religious and artistic languages. Due to the different cultures in Chinese and English, there're more differences than similarities between the animal words. English has more animal words than Chinese does. English has 155 animal words, being $31.12 \%$ of the whole vocabulary. Chinese only has 48, being $9.64 \%$ of the whole vocabulary. There're three kinds of correspondence between the two languages. First, some animal words have metaphorical meaning in English but not in Chinese. Cat carries the metaphorical meaning of an evil woman, a woman who talks bad of others, or a coward. This may be due to the superstition of Satan's pet of a cat. Badger symbolizes the American people who live in one state, who lived like a badger in winter. Goat is related with crimes and devils. It's said that devils created goats. Goat is also regarded as being inferior. Some English proverbs are with animal images, but there is none in Chinese, such as "Birds of a feather flock together. "There are no birds of this year in last." let's choose one animal word to do contrastive analysis. The animal image horse is studied. There're examples in English proverbs: 
1. All lay load on the willing horse.

2. A good horse cannot be of a bad color.

3. As distance tests a horse' strength, so time reveals a person's heart.

4. It's the saddle that makes the horse and the tailor, the man.

5. Better be the head of an ass than the tail of a horse.

6. You may take a horse to water, but you cannot force him to drink.

7. A horse that will not carry a saddle must have no oats.

8. A ragged colt may make a good horse.

9. You cannot judge the horse by the harness.

10. Better lose the saddle than the horse.

11. Never swap horses while crossing the stream.

12. The wagon must go whither the horses draw it.

Table 1.

\begin{tabular}{|l|l|}
\hline The animal used in English proverbs & The equivalent translation used in Chinese proverbs \\
\hline 1. Horse (favorable) & 1. Man (neutral) \\
\hline 2. Horse (favorable) & 2. Horse (favorable) \\
\hline 3. Horse (neutral) & 3. Horse (neutral) \\
\hline 4. Horse (neutral) & 4. Horse (neutral) \\
\hline 5. Horse (neutral) & 5. Horse (neutral) \\
\hline 6. Horse (neutral) & 6. Cow (neutral) \\
\hline 7. Horse (neutral) & 7. Man (neutral) \\
\hline 8. Horse (favorable) & 8. Young man (favorable) \\
\hline 9. Horse (neutral) & 9. Man (neutral) \\
\hline 10. Horse (favorable) & 10. General (favorable) \\
\hline 11. Horse (unfavorable) & 11. General (unfavorable) \\
\hline 12. Horse (unfavorable) & 12. Leg (unfavorable) \\
\hline
\end{tabular}

Table 2 .

\begin{tabular}{|l|l|}
\multirow{2}{*}{ "horse" in English (is translated into...) } & Horse (4) \\
\cline { 2 - 2 } & Man (4) \\
\cline { 2 - 2 } & Others (3) \\
\hline
\end{tabular}

In the twelve examples, there're four cases in which English word horse is translated literally, three cases in which it is translated into the Chinese word man, two cases in which it is translated into general in the military, one case into cow, and one case into leg. Mostly the affective meaning remain the same, except in example 1, in which the English one is favorable, while the Chinese one is neutral.

In examples 2-4, the word horse is translated directly into horse in Chinese. The three proverbs are all talking about daily experience and wisdom. English and Chinese people are both familiar with the animal horse, regarding it as human friends, using it in daily language, as a neutral word. Horses were important transport in the west and china. Western knight and cowboys ride horses, which were regarded as the symbol of bravery and wisdom. Chinese swordsman and soldiers rode horses. They loved fast and handsome horses. In china, there're lots of stories about horses and horsemen. In example 6, the word horse is translated into cow in Chinese. It shows that in Chinese society cow is also important in daily life. Cows can help with the field work, and some boys herded the cow. In example 7-12, the word horse is totally lost while the meaning is translated. This is due to the features of proverbs and different cultures. Proverbs are fixed expressions. They're the 
wisdom of people and the society and are highly textured. They have fixed patterns and fixed words, which is difficult to find equivalence in another culture. The different cultures have different ideas of the same animal, and this contributes to the understanding of horse and Ma in proverbs. In English, the horse is usually regarded as the symbol of diligence, such as:"work like a horse"and "talk horse". There're some proverbs about the horse: You can take a horse to the water, but you cannot make him drink. Better lose the saddle than the horse. Never swap horses while crossing the stream. While in China, the cow is the major animal which cultivates the land, and the two are usually associated with the characteristics of being hardworking without complaints. For example: (You can take a horse to the water, but you cannot make him drink.) (It's easier to do things than to undo the moment they are done.) (Children will naturally have their own blessings.) In short, while studying English proverbs, we shall pay more attention to the different cultural factors.

\section{Conclusion}

In conclusion, contrastive analysis is important in linguistics and foreign language learning. Existing language in the world, which has a long history of language, contains a large number of proverbs, which are the language used and refined over a long period out of the fixed phrases or short sentences. Most of them have strong sense of rhythm, form, conciseness, filled with meaning, pleasant to read. It sounds sweet, when spoken fluently, so it is loved by language learners, including foreign language learners. These Proverbs contain a wealth of cultural information, including a large number of cultural identity and cultural background, with a distinctive national and local characteristics. Therefore, when properly handled, the translation of proverbs show the relationship between language and culture, and it is necessary to retain the original beauty in the cultural practices of proverbs, but also the translated proverbs should include national and local characteristics, so as to ensure the validity of cultural transmission, and best expression.

Chinese and English proverbs have a lot of animals as metaphor in the rich vocabulary, which is rich in animal intuitives, but there are two cultures. English and Chinese thinking patterns have similarities and the similarities of the same animal will produce the same or similar implication. In view of this, the translation of some proverbs in English can be literal or the corresponding translation method. However, due to different culture, social background, mode of thinking and the aesthetic standards of the differences, the same animal may have a different meaning, and different kinds of animals may have a similar meaning. And the difference between the two languages is much greater than the similarity. There will include the word omissions, word added, vocabulary and other aspects of the conflict in Chinese and English words derived from the animal translation.

The proverbs, follow a certain principles, but its translation do not adopt a unified standard. The literal translation with the visual image, will be vivid, but sometimes foreigners can have difficulty in understanding the full meaning. However the liberal translation will lose the cultural identity. The integration of the two can be very challenging, but it's the best choice. In conclusion, in the teaching of language, teachers should master the theory of ca. and they must be also fully aware of all possible factors including schools, facilities, students, teaching materials, etc. thus in FLT, students can learn foreign language by means of comparison, imagination, and association. In this way, they can better master and use the language.

\section{References}

[1] Fries C.C. Teaching and Learning English as a Foreign Language. Ann Arbor: Wahr. 1945. pp. 9.

[2] Whorf , B. L. Language and Logic. Technological Review. 1941, pp. 68-

[3] Quirk. et al. A Grammar of the English Language. London: Longman. 1972, pp. 21.

[4] Strevens. Varieties of English. English Studies. 1964, pp. 121-125.

[5] Halliday. An Introduction to Functional Grammar. London: Edward Arnold. 1985, pp. 88.

[6] Davies. Language Testing Symposium. Oxford: Oxford University Press. 1968, pp. 12-15. 